\title{
Digital Image Analysis Of Single Rectangular Slit Fraunhofer Diffraction Patterns
}

\author{
Yuri Yogaswara ${ }^{*}$, Fourier Dzar Eljabbar Latief ${ }^{2}$ \\ ${ }^{1}$ SMA Negeri 3 Bintan, Dinas Pendidikan Provinsi Kepulauan Riau \\ Jl. Tok Sadek No.3 Tembeling, Teluk Bintan, Kab. Bintan, Provinsi Kepulauan Riau, Indonesia, 29132 \\ ${ }^{2}$ Departemen Fisika, Fakultas Matematika dan Ilmu Pengetahuan Alam, Institut Teknologi Bandung, \\ Jl. Ganesha No.10 Bandung, Indonesia, 40132
}

( Received: April 24, 2018, Revised: October 29, 2018, Accepted: August 7, 2019 )

\begin{abstract}
Study of the single rectangular slit Fraunhofer diffraction pattern has been carried out through experiments. Data acquisition was done by manually measuring the distance of the bright and dark diffraction patterns using millimeter block paper and by means of digital images analysis of the diffraction patterns. The digital images were used to obtain the bright and dark intensity data of the pattern as the function of the distance from the center of the pattern. The process of obtaining the data was carried out as follows: image acquisition, image digitization, image quality enhancement, graphics plotting and chart normalization. The data processing is done analytically and computationally using ImageJ software. The results of the digital image analysis of diffraction patterns produce an intensity graph of the distance of the diffraction pattern (I-y chart). The results from the digital image analysis approach provide an alternative method that is more accurate in the process of calculating the physical magnitude of diffraction parameters such as the wavelength of the source. One of the advantages of this method is that intensity of the diffraction pattern can be visualized as a function of the distance from the center of the screen. Although accuracy of the calculation result is not very high, the magnitude of the intensity can be observed to decrease with increasing distance of the diffraction pattern to the center of the screen. The results of the calculation of the source wavelength by means of digital image analysis provides good results compared to the manual method using the millimeter block paper. The smallest mean error of the wavelength by means of digital image analysis is $1,72 \%$ and the manual method using the millimeter block paper is $3,84 \%$. This method of measurement using digital image analysis can be used as an alternative for various position or distance-based measurement, such as the calculation of linear expansion coefficient with a single slit diffraction method.
\end{abstract}

Keywords: Fraunhofer diffraction, diffraction pattern, digital image processing, ImageJ software.

\section{INTRODUCTION}

In high school level of physics, the Fraunhofer single slit diffraction experiment for determining the source wavelength is usually done by manually measuring the distance of bright-dark diffraction patterns that produced on the screen using millimeter paper blocks or rulers. A report on such experiment [1] also used a ruler as the instrument to measure the distance of the diffraction pattern, where it was reported that the relative error in measuring the source wavelengths is $4,80 \%$. At the university level, rulers and millimeter block papers are still commonly used as measuring instruments to analyze the diffraction patterns.

In this study, an alternative method is proposed, i.e., digital images analysis by using Image J software. In addition to using the digital image analysis, the measurement using millimeter paper blocks and rulers was also conducted as a comparison. Estimation of physical quantities such as wavelengths are carried out using both methods, then the results are compared with the analytical calculation.

\footnotetext{
* Corresponding author

E-mail address: yogaswarayuri@gmail.com
} 


\section{THEORY}

In a diffraction experiment, by using a very narrow and long square slit, the fringing-effect due to the slit edges can be eliminated. The incoming rays are also assumed to be parallel and falls perpendicular to the plane of the slit. According to the Huygens principle, if all the incoming rays fall on the slit, all the points in the slit plane act as the secondary wave sources, emitting new waves called diffraction waves. In this phenomena, a plane wave falls on the slit with width of $b$, and the light passing through the slit is captured on the screen, as shown in Figure 1.

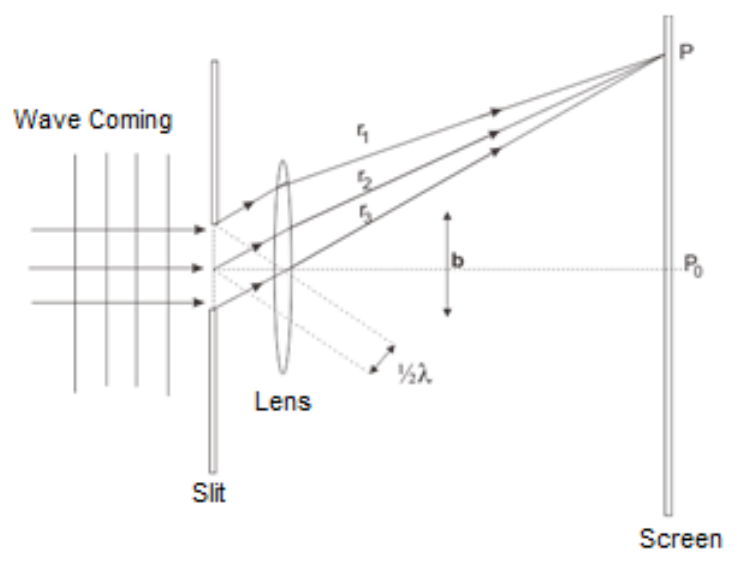

Figure 1. Diffraction by a narrow slit.

The horizontal parallel pairs of rays (not shown in the picture) that pass through the slit will be focused on $P_{o}$. Because these rays are in phase, the center point of the diffraction pattern that occurs on the screen $\left(P_{o}\right)$ has maximum intensity. If we observe other rays that form an angle of $\theta$, these rays arrive at $P$ on the screen.

$$
\frac{b}{2} \sin \theta=\frac{\lambda}{2}
$$

$b \sin \theta=\lambda$ (first minimum).

Based on Equation (1) it can be seen that for certain wavelengths, the greater the slit width $b$ the angle $\theta$ is smaller, and the narrower the slit $b$, the greater the angle $\theta$ or the wider the central area. If the slit is divided into four parts and each ray comes from the top edge of each, then the angle $\theta$ is chosen, so that $a a^{\prime}=1 / 2 \lambda$, so that $r_{1}$ and $r_{2}$ rays cancel each other at $P$. Likewise, $r_{3}$ and $r_{4}$ rays cancel out. Thus, the condition for a minimum (dark fringe pattern) to occur is:

$$
\frac{b}{4} \sin \theta=\frac{\lambda}{2}
$$

$b \sin \theta=2 \lambda$ (second minimum).

At a certain condition, the diffracted waves observed at different angles $\theta$ to the direction of the incoming wave produces zero intensity on the screen. The certain condition is related to a particular relationship as follows:

$b \sin \theta=n$, with $n \neq 0$

where $n$ is an integer, $b$ is the width of the slit and $\lambda$ is the wavelength of the incoming light. The value of $n=0$ is not included, because it relates to the observation along the direction of the incoming wave which produces maximum illumination. Based on Equation (3), in between points with zero intensity there is a maxima with a gradually decreasing intensity, which is different from the interference. The intensity of the diffraction wave as a function of $\theta$ is described in Figure 2.

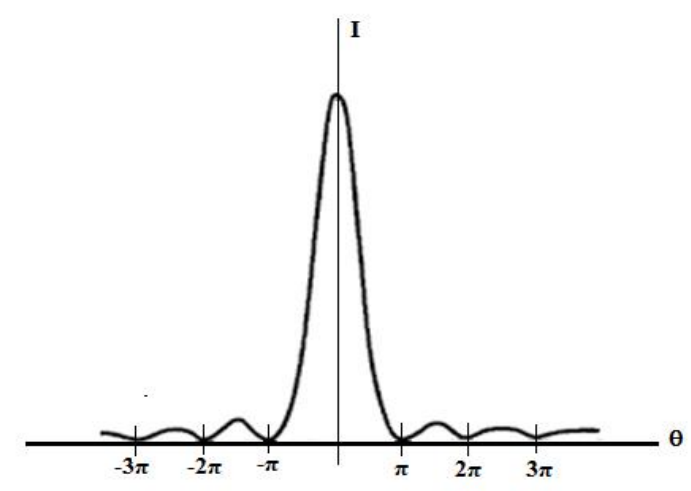

Figure 2. Distribution of the intensity of the diffraction pattern against $\theta$.

Based on Figure 2, it should be noted that the width of the central maxima is twice that of the secondary one. The intensity distribution shown in Figure 2 can be calculated by dividing the slit in very narrow slits $\Delta x$, as shown in Figure 3.

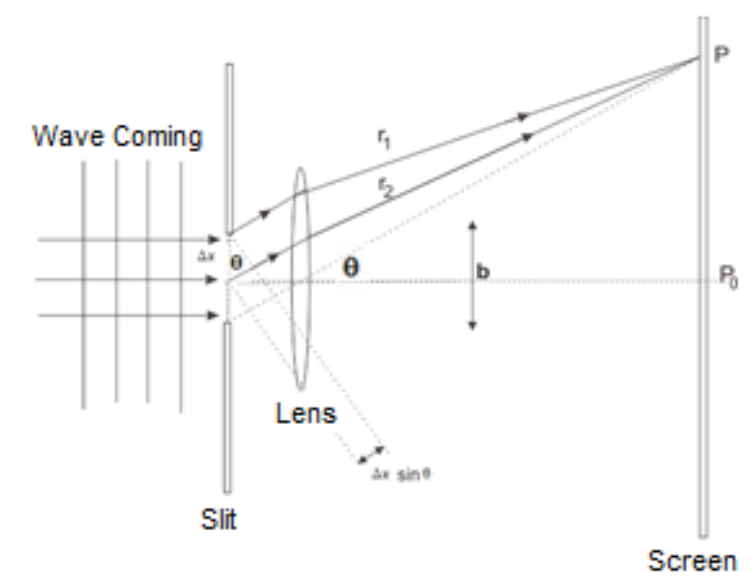

Figure 3. Geometry calculation of the intensity of the diffraction pattern.

Suppose that each interval is very narrow with the width of $\Delta x$ which acts as a secondary wave source 
with the amplitude of $\mathrm{d} E_{\theta}$ and the wave radiating in the direction of $\theta$, the phase difference is then:

$$
\begin{aligned}
& \frac{\text { phase difference }}{2 \pi}=\frac{\text { path length difference }}{\lambda} \\
& \qquad \frac{\Delta \phi}{2 \pi}=\frac{\Delta x \sin \theta}{\lambda}, \\
& \Delta \phi=\frac{2 \pi}{\lambda} \Delta x \sin \theta \text {. }
\end{aligned}
$$

which states that the phase difference increases with $x$. To obtain the amplitude in the direction of $\theta$, the wave vectors in the slit are added up. $E_{\theta}$ is the resultant amplitude at point $P$ and $E_{m}$ is the amplitude of the central diffraction pattern which can be analytically derived from the geometry as illustrated in Figure 4.

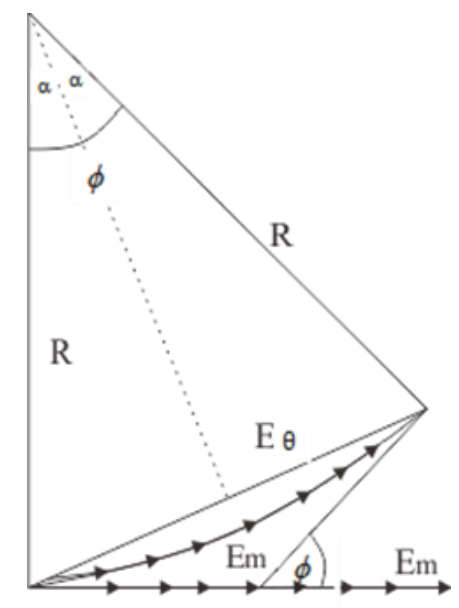

Figure 4. Resultant amplitude.

In Figure 4 the angle $\phi$ is the phase difference between the top and bottom edge rays which are diffracted by the slit in Figure 3, thus $E_{\theta}$ can be expressed as

$E_{\theta}=2 R \sin \frac{\phi}{2}$.

By using radians for $\phi$, from Figure $4 \phi$ can be calculated as

$\phi=\frac{E_{m}}{R}$.

From Equation 5 and 6, then

$$
E_{\theta}=\frac{E_{m}}{\frac{\phi}{2}} \sin \frac{\phi}{2},
$$

$\frac{E_{\theta}}{E_{m}}=\frac{\sin \alpha}{\alpha}$,

with, $\alpha=\frac{\phi}{2}$.
The phase difference he difference between the two rays is $b \sin \theta$, then it is obtained

$\phi=\frac{2 \pi}{\lambda} b \sin \theta$

From Equation 8 and Equation 9, it is obtained $\alpha=$

$\frac{\phi}{2}=\frac{\pi b}{\lambda} \sin \theta$

Substituting Equation 10 into Equation 7 produces the wave interference amplitude at any given angle $\theta$, i.e.,

$$
\frac{E_{\theta}}{E_{m}}=\frac{\sin \left(\frac{\pi b}{\lambda} \sin \theta\right)}{\frac{\pi b}{\lambda} \sin \theta}
$$

The intensity of the $I_{\theta}$ pattern is proportional to the square of the amplitude, i.e.,

$$
\frac{I_{\theta}}{I_{m}}=\left[\frac{\sin \left(\frac{\pi b}{\lambda} \sin \theta\right)}{\frac{\pi b}{\lambda} \sin \theta}\right]^{2} .
$$

Figure 5. Geometry calculation of the value approach $\sin \theta$.

In Figure 5, $D$ is the distance of the slit to the screen and $y$ is the distance of the bright/dark fringes to the central maxima. For $D>>b$, it is advantageous to use the small angle approximation where $\theta^{\prime} \approx \theta$, so that $\tan \theta \approx \sin \theta \approx \frac{y}{D}$. The intensity can be expressed as

$$
I_{\theta}=I_{m}\left[\frac{\sin \left(\frac{\pi b y}{\mathrm{D}}\right)}{\frac{\pi b y}{\mathrm{D}}}\right]^{2} \text {. }
$$

\section{EXPERIMENTAL METHOD}

Data processing for analytical calculation was carried out with the following steps: determine the $I=I_{0}$ by normalizing the intensity throughout the patterns with the intensity of the central maxima where the central maxima is set as $y=0$ (Equation (13) is used to plot the intensity); the slit width $(b)=$ $8,000 \times 10^{-5} \mathrm{~m}=0,8 \mu \mathrm{m}$, the distance of the slit to the screen $(D)=70 \mathrm{~cm}=0,7 \mathrm{~m}$, the He-Ne laser wavelength $(\lambda)=632,8 \mathrm{~nm}=6,328 \times 10^{-7} \mathrm{~m}$, and the 
distance of the two-first minima to the central $\operatorname{maxima}(y)=-4,000 \times 10^{-2} \mathrm{~m}$ to $4,000 \times 10^{-2} \mathrm{~m}$ with a width of $10 \mu \mathrm{m}=1 \times 10^{-5} \mathrm{~m}$. By substituting these values to Equation 13, the intensity plot for the distance of the diffraction pattern $I-y$ can be produced. The image processing steps is described in Figure 6.

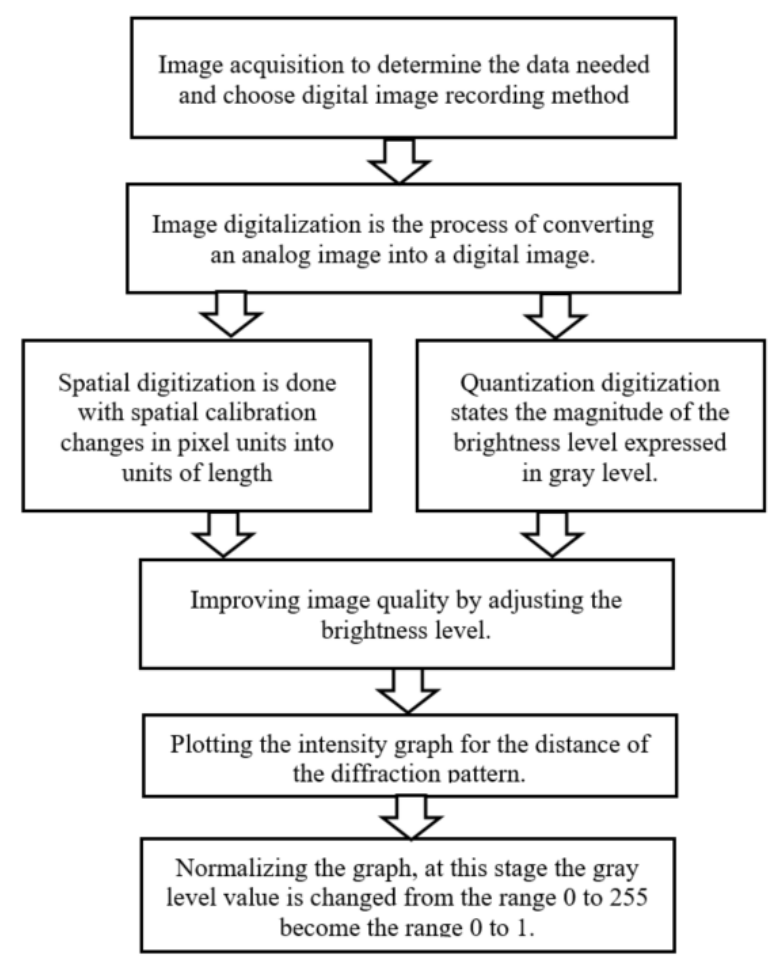

Figure 6. Flow of processing steps for digital image analysis of diffraction patterns.

\section{RESULTS AND DISCUSSION}

From the steps which has been described in Figure 6, an I-y plot was generated (see Figure 7) where the intensity is normalized. The blue curve is the $I-y$ obtained from experimental data with digital image analysis of diffraction patterns using ImageJ software, while the red curve is the $I-y$ plot which was obtained from analytical calculation. The two curves shows significant difference in terms of the minima/dark fringes intensity. The ones from the observation shows nonzero intensity for the minima patterns. The $n$-th maxima on the left and the right side of the central one have different intensity as well. The peak of these maxima are also not smooth and there are more than one observable cusp in each of the maxima peaks.

This difference can be caused by several circumstances as follows: the light captured by the camera is the reflected light from the diffraction pattern that produced on the screen, not the direct light coming out of the slit. The diffracted light is scattered as it falls on the paper which has unsmooth surface, which generates diffuse reflections. Thus the bright patterns that occur on the screen are scattered, affecting the intensity of the neighboring dark patterns. The second one is due to the experimental environment which is not a perfectly dark one. Intervention from background light from the imperfectly dark room might also affect the recorded intensity. A similar pattern was also observed in the research conducted by Brown [2]. Intensity data at the apex of each bright pattern is shown in Figure 8.

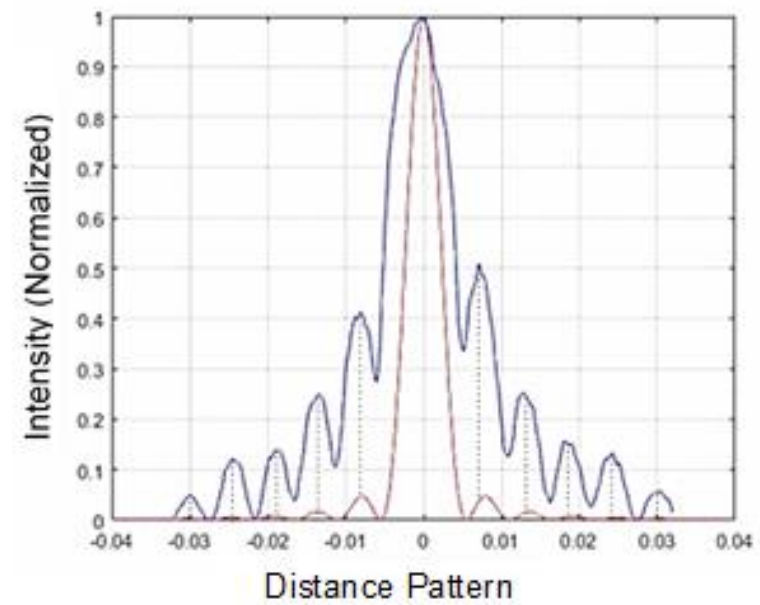

Figure 7. Graph of intensity on the distance of the diffraction pattern.

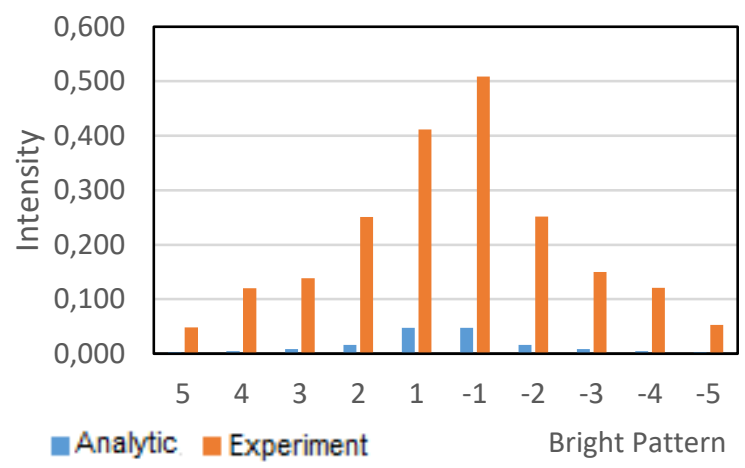

Figure 8. Comparison of the intensity of the bright pattern.

From the bright pattern intensity data, the farther away the maxima from the central maxima, the lower the intensity. The comparison of the peak intensity of the bright fringes from the analytic data and the experiment is quite different: on the left side is 1:16 (average), while on the right side 1:17 (average). Theoretically both sides should produce the same intensity. This might be caused by the camera position which is not perfectly aligned with the plane of the paper or the camera is not perfectly in an upright position. This might cause a shift in the position of the central maxima, and the bright fringes of both sides are not symmetrical. Nevertheless, the 
distance of the maxima peak at each sides from the central maxima is quite accurate (see Figure 9).

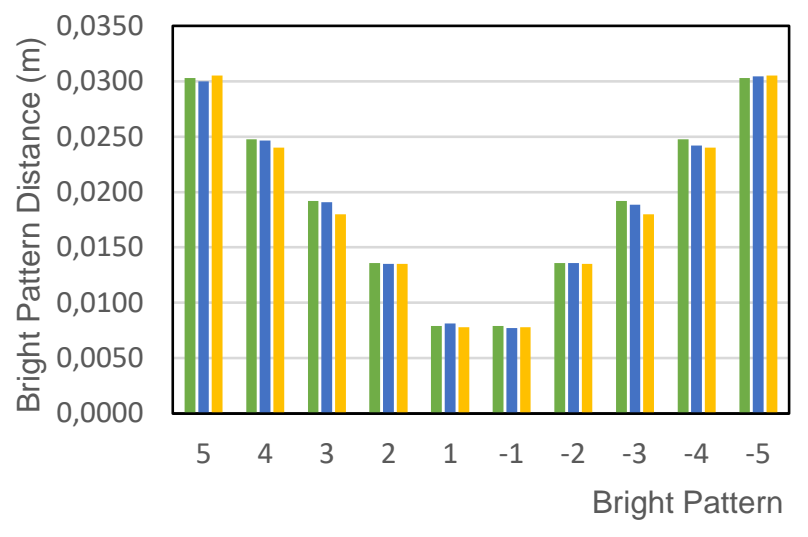

Analytic Image Analysis Manual

Figure 9. Chart comparison of the distance of the light to the center of the bright pattern.

Figure 9 is the plot of bright pattern distance to the central maxima, measured for the first five maxima. The presented data are the calculation from analytical calculation, the data from image analysis using ImageJ software and the data from manual measurement using millimeter block paper. When compared with analytic data between the results of the analysis of digital images and manual analysis data, the difference is very small. Thus we can say that for both methods, the distance of the peak of bright fringes to the central maxima are quite accurate. The calculated wavelength of the source light is presented in Table 1.

Table 1a. Wavelength Data Used, Left Side Section.

\begin{tabular}{ccc}
\hline $\mathrm{n}$ & $\begin{array}{c}\lambda \\
\text { Image Analysis }(\mathrm{m})\end{array}$ & $\begin{array}{c}\lambda \\
\text { Manual Analysis }(\mathrm{m})\end{array}$ \\
\hline 1 & $6,2041 \times 10^{-7}$ & $5,9429 \times 10^{-7}$ \\
2 & $6,1714 \times 10^{-7}$ & $6,1714 \times 10^{-7}$ \\
3 & $6,2274 \times 10^{-7}$ & $5,8776 \times 10^{-7}$ \\
4 & $6,2585 \times 10^{-7}$ & $6,0952 \times 10^{-7}$ \\
5 & $6,2338 \times 10^{-7}$ & $6,3377 \times 10^{-7}$ \\
\hline Average & $6,2190 \times 10^{-7}$ & $6,0849 \times 10^{-7}$ \\
Error & $1,72 \%$ & $3,84 \%$ \\
\hline
\end{tabular}

Table 1b. Wavelength Data Used, Right Side Section.

\begin{tabular}{ccc}
\hline $\mathrm{n}$ & $\begin{array}{c}\lambda \\
\text { Image Analysis }(\mathrm{m})\end{array}$ & $\begin{array}{c}\lambda \\
\text { Manual Analysis }(\mathrm{m})\end{array}$ \\
\hline 1 & $5,87771 \times 10^{-7}$ & $5,9429 \times 10^{-7}$ \\
2 & $6,20411 \times 10^{-7}$ & $6,1714 \times 10^{-7}$ \\
3 & $6,15744 \times 10^{-7}$ & $5,8776 \times 10^{-7}$ \\
4 & $6,14968 \times 10^{-7}$ & $6,0952 \times 10^{-7}$ \\
5 & $6,32282 \times 10^{-7}$ & $6,3377 \times 10^{-7}$ \\
\hline Average & $6,1424 \times 10^{-7}$ & $6,0849 \times 10^{-7}$ \\
Error & $2,93 \%$ & $3,84 \%$ \\
\hline
\end{tabular}

In the analysis the error is calculated as follows

$$
\left|\frac{\text { Reference Data }- \text { Experimental Data }}{\text { Reference Data }}\right| \times 100 \%
$$

From Table 1a, the wavelength obtained from the digital image analysis from the left $I-y$ graph is $6,2190 \times 10^{-7} \mathrm{~m}$ (average) with an error of $1,72 \%$ while from Table $1 \mathrm{~b}$ the results from the digital image analysis from the $I-y$ chart of the right side is $6,1424 \times$ $10^{-7} \mathrm{~m}$ (average) with error of $2,93 \%$ compared to manual analysis data $6,0849 \times 10^{-7} \mathrm{~m}$ with error of $3,84 \%$. These errors can also be derived from inaccurate image quality due to the effect of resolution. However, we cannot do a definite analysis because there is no data collection for different resolutions.

\section{CONCLUSION}

Digital image analysis methods provide an alternative method that is more accurate in calculating the physical quantities of diffraction events, i.e., the width of the slit and the wavelength of the beam used. The advantage of this method is that it can produce a display of intensity plot of the diffraction pattern. Even though the results are not quite accurate, especially the intensity peaks of the bright fringes, the plot can provide a good illustration that the magnitude of the intensity of the light pattern decreases with increasing distance of the diffraction pattern to the central maxima. The results of the calculation of the wavelength of the light used by the method of digital image analysis provides good results compared to the manual method using a millimeter block paper. The smallest error rate is in the measurement of wavelength by the method of digital image analysis is $1,72 \%$ while the one obtained from the manual method using a millimeter paper measuring block is $3,84 \%$. This method can be used as an alternative method on the concept of digital image-based material, such as the calculation of long expansion coefficient values with a single slit diffraction method.

\section{ACKNOWLEDGMENT}

The author would like to thank the Department of Physics, the Faculty of Mathematics and Natural Sciences (FMIPA) ITB for providing financial support through Student Activity Assistance (BKM) and Basic Physics laboratory assistants - BSCA who have assisted in the provision of measuring instruments and data collection of this research. 


\section{REFERENCES}

[1] S. Anuar,et al., Pengembangan Adjustable Single Slit Interference Kit (ASSIK) sebagai Media Pembelajaran Difraksi Cahaya pada Celah Tunggal Kelas XII, Jurnal EduFisika, Vol.01 No.01, 13-17, 2016.

[2] D. Brown and A.J Cox, Innovative Uses of Video Analysis, Journal of Physics Teacher, 47, 145-149, 2009.

[3] J. Walker, D. Halliday, and R. Resnick, Fundamentals of Physics, 10th Edition, John Wiley \& Sons, Inc, United of States of America, 1081-1090, 2014.

[4] R. A Serwey and J.W Jewett, Physics for Scientists and Engineers with Modern Physics, Ninth Edition, 20 Channel Center Street, Boston, 573-576, 2008.

[5] S. Mezouari and R. Harvey, Validity of Fresnel and Fraunhofer Approximations in Scalar Diffraction, Journal of Optics, 5, 86-91, 2003.
[6] K. Suardhika, Tugas Mata Kuliah Fisika Dasar : Difraksi dan Aplikasinya, Univesitas Pendidikan Ganesha (UNDIKSHA), Singaraja, 2012.

[7] Sastra, Tugas Mata Kuliah Fisika Dasar : Difraksi Cahaya, Universitas Pendidikan Indonesia (UPI), Bandung, 2015.

[8] D. Morin, Interference and diffraction, first Edition, Havad University, Massachusetts, 2010.

[9] C. Iswahyudi, Tugas Mata Kuliah Komputer Grafis: Pengolahan Citra Digital, Sekolah Tinggi Ilmu Komputer (STIKOM), Bali, 2013.

[10] D. S. Tiani, Skripsi: Penajaman Distribusi Intensitas Cahaya Pada Difraksi Fraunhofer Celah Tunggal Persegi dengan Ditigal Image Processing, Universitas Negeri Yogyakarta (UNY), Yogyakarta, 2015. 